\title{
Evaluation studies of Sustainable Development of highway construction based on entropy weight-fuzzy comprehensive method
}

\author{
Yu HE \\ Business School, Hohai University, Nanjing, Jiangsu,211100,China \\ hzq1309@163.com
}

\begin{abstract}
Key words: highway, sustainable development, entropy weight-fuzzy comprehensive evaluation method

Abstract: The sustainable development of highway construction project is a level reflection to develop highway project for a country. With the speeding up of industrialization and urbanization, social and economic benefits brought by network highway construction are more obvious, while the environmental pollution is becoming more serious. Based on the analysis of highway sustainable development, the entropy weight-fuzzy comprehensive evaluation method is proposed to evaluate the status of sustainable development of highway construction. And the Shanghai-Nanjing highway (Jiangsu section) was taken as an example to strategically evaluated regional highway project construction from three aspects including economy, society and environment.
\end{abstract}

\section{Introduction}

It is a vital role that highway construction to optimize the structure of the transportation and alleviate the pressure of the transportation in our country. By the end of 2014, China's highway traffic mileage of 111950 kilometers ranks first in the world, and to speed up the material information circulation, enhance the level of people's life has played a positive role. But with the development of highway construction, will inevitably bring a lot of negative effects, such as traffic congestion, energy consumption, and environmental degradation and so on. Under building "a resource-conserving and environment-friendly" society background, the construction of the highway must consider the regional ecological environment and protect the original ecosystem. Therefore, Development of highway construction projects is very necessary under the guidance of the sustainable development. From the point view of systematic perspective, we must properly handle the relationship between resources, environment and economic development, and coordinate the traffic system and the relationship between the economic and social system.

\section{The connotation of sustainable development on the highway}

It is a complex system of the highway construction. The system should not only meet the highway transportation system and coordinated development of comprehensive transportation system, and should reflect the characteristics of the sustainable development of economy and environment. Therefore, highway construction sustainable development as a new concept of thinking and concept of development, through the lasting development capacity and transportation sustainable development state, to meet and promote the harmonious development of man and the environment, finally realizes the overall progress of human society. In its book "sustainable transportation: the key policy changes" written by World Bank, in the proposed the concept of sustainable transportation, it argues that sustainable transport mainly includes three aspects, namely economic sustainable, environmental and ecological sustainable and sustainable society. Sustainable transport requirement in the process of development of transportation should not only consider the economic 
effect produced by the transportation itself. Which is more important to give full consideration to the transport of external is the utility and negative utility. Specifically, we should understand that from the following three aspects.

The relationship between highway construction and economic system: Economic system is a closely linked with the environment of open system, has the typical characteristics of dissipative structure, the overall system of balance and internal mechanism of the nonlinear system. As the main way of social economic system and the external exchanges, the sustainable development of the transportation system can enhance the social external environment fluctuation reflects the sensitive degree of the economic system, promote social economic system the positive evolution of dissipative structure. And the development of social economy also will be beneficial to the sustainable development of regional traffic with momentum.

The relationship between highway construction and environmental system: Transport system in promoting the development of the society ,at the same time, also brought a series of environmental problems, such as air pollution, water pollution, soil degradation, noise pollution and visual pollution. Regional transportation to maintain sustainable development, should fully take the traffic environment capacity into the consideration, must be as far as possible under the minimum pollution to realize maximum limit traffic capacity. When economic development up to a certain stage, carrying capacity of regional resources is likely to approach a limited value, the development of the regional transportation system is restricted, needing through the structural adjustment or buffering the pressure on the other ways, otherwise it may halt, or even become a "bottleneck" of regional development. Usage of regional resource, on the other hand, is a dynamic development process. It doesn't often confine to the area of existing resources carrying capacity "supreme".

The relationship between highway construction and social system: Highway construction can be used as a kind of important way to break the original between social structure and social balance. In under the condition of poor traffic conditions, especially in remote mountain villages, the circle of people's life is relatively small, and people's material life is very poor. Daily consumption only relies on local agriculture production as the main source. The highway construction on this area, can promote people's further exchanges on different areas, promoting the exchange of information, products at the same time. The link between each other more closely and it is more convenient with communication of culture and education, breaking the isolated closed state, promoting the development of the culture education career and having a significant impact on the health of a region.

\section{The establishment of the evaluation of the highway system sustainable development}

The evaluation index system of the highway system sustainable development According to the view of Shuyu Xu (2006), Frey, B.S. (2008), Shenggen Fan (2008), Joe leong (2008), combining the above the highway construction project of sustainable development of economy, society and environment influence factors analysis of three sub functions, propose the evaluation index system of highway construction project of sustainable development. The concrete mechanism is shown in Table. 1. 
Table. 1 The evaluation system of the sustainable development of highway construction

\begin{tabular}{|c|c|c|}
\hline $\begin{array}{l}\text { first grade } \\
\text { indexes }\end{array}$ & $\begin{array}{l}\text { second grade } \\
\text { indexes }\end{array}$ & third grade indexes \\
\hline \multirow{7}{*}{$\begin{array}{c}\text { economic } \\
\text { sustainable } \\
\mathrm{S}_{1}\end{array}$} & \multirow{3}{*}{$\begin{array}{l}\text { project economy } \\
\mathrm{S}_{11}\end{array}$} & The change rate of passager and freight volume $S_{111}$ \\
\hline & & The change rate of highway roll income $S_{112}$ \\
\hline & & Return on capital $\mathrm{S}_{113}$ \\
\hline & \multirow{4}{*}{$\begin{array}{l}\text { regional conomy } \\
\mathrm{S}_{12}\end{array}$} & Regional per capita GDP $S_{121}$ \\
\hline & & Regional per capita income $S_{22}$ \\
\hline & & The growth rate of regional finance income $S_{123}$ \\
\hline & & The change rate of industrial structure $\mathrm{S}_{124}$ \\
\hline \multirow{7}{*}{$\begin{array}{c}\text { Social } \\
\text { sustainable } \\
\mathrm{S}_{2}\end{array}$} & \multirow{4}{*}{$\begin{array}{l}\text { Social Development } \\
\qquad \mathrm{S}_{21}\end{array}$} & The change rate of engers coefficient $S_{211}$ \\
\hline & & The change rate of geordie coefficient $S_{212}$ \\
\hline & & The increasing rate of employment $S_{213}$ \\
\hline & & The change rate of social charity expense $S_{214}$ \\
\hline & \multirow{3}{*}{$\begin{array}{l}\text { population quality } \\
\qquad \mathrm{S}_{22}\end{array}$} & The change rate of degree of education $S_{221}$ \\
\hline & & The change rate of average life $S_{222}$ \\
\hline & & The change rate of patent quantity $S_{223}$ \\
\hline \multirow{8}{*}{$\begin{array}{c}\text { Environmental } \\
\text { Sustainable } \\
\mathrm{S}_{3}\end{array}$} & \multirow{2}{*}{$\begin{array}{c}\text { land resources } \\
\mathrm{S}_{31} \\
\end{array}$} & Water Loss Rate $S_{311}$ \\
\hline & & The rate of land embezzlement $S_{312}$ \\
\hline & \multirow{2}{*}{$\begin{array}{l}\text { ecological resources } \\
\mathrm{S}_{32}\end{array}$} & ecological diversity $S_{321}$ \\
\hline & & Broken rate of ecological sensitive area $S_{322}$ \\
\hline & \multirow{2}{*}{$\begin{array}{l}\text { air resources } \\
\mathrm{S}_{33}\end{array}$} & $\mathrm{CO}, \mathrm{NO}_{2}$ emission $\mathrm{S}_{331}$ \\
\hline & & Tail gas emission $\mathrm{S}_{332}$ \\
\hline & \multirow{2}{*}{$\begin{array}{c}\text { system of } \\
\text { environmental } \\
\text { protection } \\
\mathrm{S}_{34} \\
\end{array}$} & $\begin{array}{l}\text { The increasing rate of expenses of environmental } \\
\text { protection } S_{341}\end{array}$ \\
\hline & & $\begin{array}{l}\text { The increasing rate of direct investment of } \\
\text { environmental protection } S_{342}\end{array}$ \\
\hline
\end{tabular}

\section{The evaluation model of the highway system sustainable development}

Fuzzy comprehensive evaluation (FCE) is based on fuzzy mathematics, the fuzzy relationship synthetic principle, classified some boundaries are not clear, quantitative factors are not clear, not easily quantified, and a method for comprehensive evaluation. Highway construction sustainable development is a multi-factor, multi-phase coupling of complex giant system, the complexity of economic, social and environmental factors between showed great uncertainty and randomness.

The degree of sustainable development division has relativity and fuzziness, so the fuzzy comprehensive evaluation method can consider the evaluation factor and equivalent levels of uncertainty. But some attention of fuzzy comprehensive evaluation is the expert's experience and knowledge, without considering the specific actual data, the entropy weight method is based on the original data for the selected evaluation index for empowerment, less affected by human factors. Therefore the combination of the entropy weight and fuzzy comprehensive evaluation method, make full use of the experience of expert judgment, and to evaluate reasoning on objective data, has the relative superiority and scientificity.

According to the literature, to shape of each evaluation index, gives a quantitative evaluation criterion, and then the corresponding meaning of sustainable development, determine the sustainable evaluation level set. Set up evaluation index set, for the sustainable development of highway construction for evaluation index number is $U=\left(u_{1}, u_{2}, \cdots u_{n}\right)$; Degree of sustainable 
development evaluation level sets is $V=\left(v_{1}, v_{2}, \cdots v_{m}\right), \mathrm{m}$ for the sustainable development level. We assume that there have $\mathrm{t}$ evaluators, form the original evaluation matrix:

$$
S=\left(r_{i j}\right)_{n \times t}=\left(\begin{array}{lll}
r_{11} & r_{12} \cdots & r_{1 t} \\
r_{21} & r_{22} \cdots & r_{2 t} \\
a_{n 1} & r_{n 2} \cdots & a_{n t}
\end{array}\right)
$$

Among them, $r_{i j}(i=1,2, \cdots n, j=1,2 \cdots t)$ for the first $\mathrm{j}$ evaluators of the first kind of evaluation index to evaluate the sustainability of results, the evaluation results in level set of $V=\left(v_{1}, v_{2}, \cdots v_{m}\right)$.

Entropy weight method is a kind of objective empowerment, this article in the process of using the entropy weight method to determine matrix $\mathrm{R}$ to normalization of data processing using $0-1$ standardization, standardization among them in order to avoid matrix in 0 , the $r_{\max }$ and $r_{\min }$ to adjust up and down $20 \%$.

Determine the membership function of commonly used vector normalization method, linear transformation method, and the method, the effect of such structural approach of the membership function can be regarded as the rectilinear normalization method, the linear relationship is refers to the assumption that the indicator assessment and a linear relationship with the actual value, the value of proportion along with the actual values change, on the basis of this point and the actual situation of development and change things often don't meet, so many scholars carried out the structure of the nonlinear membership function. Among them, the drop half trapezoid distribution method is one of the commonly used method. This paper also used this method, the formula are shown in Eq.1, Eq.2 and Eq.3:

$$
\begin{aligned}
& \varepsilon_{i 1}= \begin{cases}1 & x_{i} \leq v_{i 1} \\
\frac{v_{i 2}-x_{i}}{v_{i 2}-v_{i 1}} & v_{i 1}<x_{1}<v_{i 2} \\
0 & x_{1} \leq v_{i 2}\end{cases} \\
& \varepsilon_{i j}=\left\{\begin{array}{lc}
0 & \mathrm{x}_{\mathrm{i}} \leq \mathrm{v}_{\mathrm{i}(j-1)} \text { or } \mathrm{x}_{\mathrm{i}} \geq \mathrm{v}_{\mathrm{i}(j+1)} \\
\frac{\mathrm{x}_{\mathrm{i}}-\mathrm{v}_{\mathrm{i}(j-1)}}{\mathrm{v}_{\mathrm{ij}}-\mathrm{v}_{\mathrm{i}(j-1)}} & \mathrm{v}_{\mathrm{i}(j-1)}<\mathrm{x}_{\mathrm{i}}<\mathrm{v}_{\mathrm{ij}} \\
\frac{\mathrm{v}_{\mathrm{i}(j+1)}-\mathrm{x}_{\mathrm{i}}}{\mathrm{v}_{\mathrm{i}(j+1)}-\mathrm{v}_{\mathrm{ij}}} & \mathrm{v}_{\mathrm{ij}}<\mathrm{x}_{\mathrm{i}}<\mathrm{v}_{\mathrm{i}(j+1)}
\end{array}\right. \\
& \varepsilon_{i t}=\left\{\begin{array}{lc}
0 & \mathrm{x}_{\mathrm{i}} \leq \mathrm{v}_{\mathrm{i}(t-1)} \\
\frac{\mathrm{x}_{\mathrm{i}}-\mathrm{v}_{\mathrm{i}(t-1)}}{\mathrm{v}_{\mathrm{it}}-\mathrm{v}_{\mathrm{i}(\mathrm{t}-1)}} & \mathrm{v}_{\mathrm{i}(\mathrm{t}-1)}<\mathrm{x}_{\mathrm{i}}<\mathrm{v}_{\mathrm{it}} \\
1 & \mathrm{x}_{\mathrm{i}}>\mathrm{v}_{\mathrm{it}}
\end{array}\right.
\end{aligned}
$$

Among them, $x_{i}$ is the first $\mathrm{i}$ kind of the actual value of evaluation indexes, $v_{i j}$ for the first $\mathrm{j} A$ sustainable level in the first evaluation index of the initial value. According to the membership degree, the establishment of evaluation index and the sustainable degree fuzzy relation between evaluations grades membership degree matrix A.

$$
A=\left(\begin{array}{lll}
\varepsilon_{11} & \varepsilon_{12} \cdots & \varepsilon_{1 t} \\
\varepsilon_{21} & \varepsilon_{22} \cdots & \varepsilon_{2 t} \\
\varepsilon_{n 1} & \varepsilon_{n 2} \cdots & \varepsilon_{n t}
\end{array}\right)
$$

According to the above steps 2 and 3 to get the weight vector and fuzzy comprehensive evaluation, the membership degree matrix to compute the formula for the $Z=W \times A$, the weight vector $\mathrm{W}$ as the entropy weight method, A for fuzzy membership degree matrix. 


\section{The specific example of the sustainable development evaluation of highway construction}

Total length of $258.4 \mathrm{~km}$, the Jiangsu section of Shanghai-Nanjing expressway across the land, $46000 \mathrm{mu}$. East Huning expressway (Jiangsu section) in Suzhou flower bridge, west to Nanjing horses, roadbed width of $26 \mathrm{~m}, 21.5 \mathrm{~m}$ wide road, four lanes. The construction of the Shanghai-Nanjing expressway to Nanjing and suxichang metropolitan circle and Shanghai city circle, and shorten the space and time distance between the five cities, providing traffic conditions for the economic development of Jiangsu, and become one of the causes of foreign assets.

Highway construction from the sustainable economic and social sustainability evaluation considering sustainable and environmentally sustainable, combining with the consulting experts and opinion, and from the project economy, regional economic and social development and other aspects detailed evaluation, evaluation index system of concrete are shown in table 1. Sustainable evaluation level of reference literature, and on the index system of 22 indexes to establish the degree of sustainable development evaluation level sets $\mathrm{V}=$ (unsustainable $\mathrm{V} 1$, weak basic sustainable V2, basic sustainable V3 and strong sustainable V4, strong sustainable V5) that including five levels of evaluation.

For each index of sustainable development, the influence of selected 10 leading experts to evaluate the five rating scale method is adopted, and the formation of the original matrix, the formula according to the standardization of original data standardization, get the rating matrix, limited to space limitations, evaluation matrix is not specifically listed, get 22 indexes of entropy vector set $\mathrm{W}=\{0.0631,0.0711,0.1704,0.0534,0.0433,0.0247,0.0263,0.0513,0.0447$, $0.0571,0.0339,0.0228,0.0177,0.0135,0.0317,0.0598,0.0497,0.0339,0.0393,0.0422$, $0.0284,0.0217\}$

According to the formula 2, control the actual value of the evaluating indices, and can calculate the membership degree, specific data are shown in table 2

Table. 2 The results of comprehensive evaluation

\begin{tabular}{|c|c|c|c|c|c|c|c|c|c|c|c|c|}
\hline \multicolumn{2}{|c|}{$\begin{array}{l}\text { The evaluation } \\
\text { index }\end{array}$} & $\mathbf{S}_{111}$ & $S_{112}$ & $S_{113}$ & $S_{121}$ & $S_{122}$ & $S_{123}$ & $S_{124}$ & $S_{211}$ & $S_{212}$ & $\mathbf{S}_{213}$ & $S_{214}$ \\
\hline \multicolumn{2}{|c|}{ The actual value } & 4.4 & 4 & 4.1 & 4.1 & 3.5 & 3.8 & 3 & 3.3 & 2.9 & 2.5 & 3.1 \\
\hline \multirow{5}{*}{$\begin{array}{c}\text { The } \\
\text { sustainable } \\
\text { development } \\
\text { level }\end{array}$} & $\mathbf{V}_{1}$ & 0 & 0 & 0 & 0 & 0 & 0 & 0 & 0 & 0 & 0 & 0 \\
\hline & $\mathbf{V}_{2}$ & 0 & 0 & 0 & 0 & 0 & 0 & 0 & 0 & 0.1 & 0 & 0 \\
\hline & $\mathbf{V}_{3}$ & 0 & 0 & 0 & 0 & 0.5 & 0.2 & 1 & 0.7 & 0.9 & 0.5 & 0.9 \\
\hline & $V_{4}$ & 0.6 & 1 & 0.9 & 0.9 & 0.5 & 0.8 & 0 & 0.3 & 0 & 0.5 & 0.1 \\
\hline & $\mathbf{V}_{5}$ & 4 & 0 & 0.1 & 0.1 & 0 & 0 & 0 & 0 & 0 & 0 & 0 \\
\hline \multicolumn{2}{|c|}{$\begin{array}{c}\text { The evaluation } \\
\text { index }\end{array}$} & $\mathbf{S}_{221}$ & $S_{222}$ & $\mathbf{S}_{223}$ & $S_{311}$ & $S_{312}$ & $S_{321}$ & $S_{322}$ & $S_{331}$ & $S_{332}$ & $S_{341}$ & $\mathbf{S}_{342}$ \\
\hline \multicolumn{2}{|c|}{ The actual value } & 3.7 & 3.5 & 3.5 & 3.6 & 3.7 & 3.2 & 3.8 & 2.1 & 2.9 & 3.1 & 3.6 \\
\hline \multirow{5}{*}{$\begin{array}{c}\text { The } \\
\text { sustainable } \\
\text { development } \\
\text { level }\end{array}$} & $\mathbf{V}_{1}$ & 0 & 0 & 0 & 0 & 0 & 0 & 0 & 0 & 0 & 0 & 0 \\
\hline & $V_{2}$ & 0 & 0 & 0 & 0 & 0 & 0 & 0 & 0.9 & 0.1 & 0 & 0 \\
\hline & $V_{3}$ & 0.3 & 0.5 & 0.5 & 0.4 & 0.3 & 0.8 & 0.2 & 0.1 & 0.9 & 0.9 & 0.4 \\
\hline & $V_{4}$ & 0.7 & 0.5 & 0.5 & 0.6 & 0.7 & 0.2 & 0.8 & 0 & 0 & 0.1 & 0.6 \\
\hline & $V_{5}$ & 0 & 0 & 0 & 0 & 0 & 0 & 0 & 0 & 0 & 0 & 0 \\
\hline
\end{tabular}

According to the entropy weight vector and membership degree matrix, use the fuzzy comprehensive evaluation, and get:

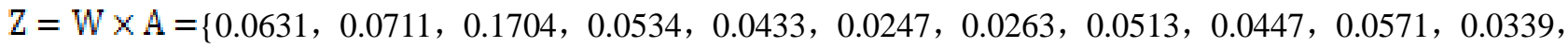


$0.0228,0.0177,0.0135,0.0317,0.0598,0.0497,0.0339,0.0393,0.0422,0.0284,0.0217\} \times$

$\left\{\begin{array}{cccccccccccccccccccccc}0 & 0 & 0 & 0 & 0 & 0 & 0 & 0 & 0 & 0 & 0 & 0 & 0 & 0 & 0 & 0 & 0 & 0 & 0 & 0 & 0 & 0 \\ 0 & 0 & 0 & 0 & 0 & 0 & 0 & 0 & 0.1 & 0 & 0 & 0 & 0 & 0 & 0 & 0 & 0 & 0 & 0.9 & 0.1 & 0 & 0 \\ 0 & 0 & 0 & 0 & 0.5 & 0.2 & 1 & 0.7 & 0.9 & 0.5 & 0.9 & 0.3 & 0.5 & 0.5 & 0.4 & 0.3 & 0.8 & 0.2 & 0.1 & 0.9 & 0.9 & 0.4 \\ 0.6 & 1 & 0.9 & 0.9 & 0.5 & 0.8 & 0 & 0.3 & 0 & 0.5 & 0.1 & 0.7 & 0.5 & 0.5 & 0.6 & 0.7 & 0.2 & 0.8 & 0 & 0 & 0.1 & 0.6 \\ 0.4 & 0 & 0.1 & 0.1 & 0 & 0 & 0 & 0 & 0 & 0 & 0 & 0 & 0 & 0 & 0 & 0 & 0 & 0 & 0 & 0 & 0 & 0\end{array}\right\}^{T}$

$=(0,0.0441,0.3524,0.5274,0.0476)$

Combined with the evaluation of sustainable development level can be concluded that the sustainable development of shanghai-Nanjing high-speed level for strong sustainable. In fact, is put forward in the construction of the Jiangsu section of shanghai-Nanjing high-speed "harmonious" concept, and according to the actual project situation made more innovation. If use "graph analysis method" to replace the traditional "chasing method of contour line selection, the drainage system adopted comprehensive drainage system, follow the split between the pond road, road in the design field separation principle, make the highway drainage system sui generis, fully consider the environment in the process of construction, the value of aesthetics, history, and resources, achieved good environmental benefit and social efficiency. At the same time, the shanghai-Nanjing high-speed between Nanjing and Shanghai city in the south of Jiangsu into a line, speeding up the development of export-oriented economy in the region and technology spillover, makes the region become the most developed economy in our country and one of the most stable and good ecological environment.

\section{Conclusions}

The sustainable development of the highway construction projects, reflect the economic development of a country development highway project scale and level of important symbol. The highway construction project of sustainable development is to realize the highway construction and economic development, social progress and human ecological construction, environmental protection, the relationship between the degree of technology development, become a matter of the sustainable and healthy development of human society and influence the core issue of survival for many generations. Therefore, reasonable construction, highway construction projects management, realize sustainable development of highway construction project, will be the construction of the national economy a long-term and important task. As a result, the sustainable development of highway construction projects, using entropy weight of fuzzy comprehensive evaluation method from the sub aspects of economics, society, environment, make the evaluation more scientific and practical.

\section{References}

[1]Yi LIU,Yuanhua LIANG, Langqing SHI. Journal of Beijing jiaotong university, 2007(03):1-5. In Chinese

[2] Shengrui ZHANG. Highway traffic sustainable development question research - theoretical model and application. People Traffic Press, 2005. In Chinese

[3] Yongbin Liu, Fengchun Yang. Research of soil and water conservation, 2005, 6(12): 46-49. In Chinese

[4] Shuyu XU, Yuanhua JIA. Transportation Systems of Engineering and Information Technology, 2006(1), 118-122. In Chinese

[5] Frey,B.S.,F.Schneider,W.W.Pommerehne. Economists'Opinions on Environmental Policy Instruments:Analysis of a Survey.Journal of Environmental Economics and Management,No.12 
2008.

[6] Shenggen Fan, Connie Chan-Kang. Regional Road Development, Rural and Urban Poverty: Evidence from China. Transport Policy, 2008(05), 305-314.

[7] Guohua LIANG, Ronguo MA. The Chinese and Foreign Road, 2008(04), 269-273. In Chinese

[8] Shuili CHEN, Jinggong LI, Xianggong WANG. Fuzzy set Theory and Its Application. Science press, 2005. In Chinese

[9] Sui ZHANG, Mei ZHANG. Journal of management, 2010, 7(1): 34-42. In Chinese 